\title{
Strahleninduzierte Strahlenschutzsubstanzen*
}

\author{
Von K. Sommermeyer und H. Magnus \\ Aus dem Radiologischen Institut der Universität Freiburg Br. und den Städtischen \\ Krankenanstalten Karlsruhe (Röntgeninstitut) \\ (Z. Naturforschg. 18 b, 17-23 [1963]; eingegangen am 7. April 1962)
}

\begin{abstract}
Bestrahlt man B. coli auf Agar, der vorbestrahlt ist, so stellt man fest, daß in der Coli-Zelle ein Antagonismus zwischen der direkten Bestrahlung und aus dem Agar stammenden aktiven Substanzen besteht. Die Wirkung der im Agar unter dem Einfluß der Bestrahlung entstehenden Schutzsubstanzen ist insofern der Wirkung der bekannten chemisch stabilen Schutzsubstanzen vergleichbar, als sie nur dann vor den Folgen der direkten Bestrahlung schützen, wenn sie bereits vor der direkten Bestrahlung in die Bakterien gelangt sind. Sie besitzen im Agar eine mittlere Lebensdauer von 30 bis $60 \mathrm{sec}$ und in der Coli-Zelle, nachdem sie dort adsorbiert sind, gleichfalls eine mittlere Lebensdauer von $30-60$ Sekunden.
\end{abstract}

Bestrahlt man Agar mit energiereichen Strahlen von genügend hoher Dosisleistung und bringt unmittelbar nach der Bestrahlung auf den Agar B. coli auf, so stellt man fest, daß die Bakterien durch Substanzen, welche von dem Agar zu den Bakterien hindiffundieren, inaktiviert werden. Bringt man $B$. coli auf den Agar nicht unmittelbar nach dessen Bestrahlung auf, sondern läßt Zeit verstreichen, so ergibt sich, daß die inaktivierenden Substanzen im Agar eine begrenzte Lebensdauer (im Mittel bis etwa $20 \mathrm{sec})^{1}$ besitzen.

Bestrahlt man die Bakterien auf unbestrahltem Agar und somit Bakterien und Agar gleichzeitig, so kommt zu der direkten Strahlenwirkung auf die Bakterien noch die indirekte Strahlenwirkung durch die aus dem Agar zu den Bakterien hin diffundierenden Moleküle hinzu. Durch eine quantitative Untersuchung ergibt sich jedoch, daß bei der gleichzeitigen Bestrahlung von Bakterien und Agar in den Bakterien die Wirkungen von direkter Bestrahlung und Agarsubstanzen keineswegs unabhängig voneinander sind. Man erhält vielmehr eine viel geringere Inaktivierung als erwartet ${ }^{2}$.

Dieser Befund findet nach Durchführung umfangreicher Versuchsreihen seine Erklärung im wesentlichen dadurch, daß grundsätzlich in der Coli-Zelle ein Antagonismus zwischen der direkten Bestrahlung und den aus dem Agar stammenden aktiven Substanzen besteht. Die Wirkung der im Agar unter dem Einfluß der Bestrahlung entstehenden aktiven Substanzen ist insofern der Wirkung der bekannten chemisch stabilen Strahlenschutzsubstanzen ver-

* Herrn Professor H. Schreiber zum 60. Geburtstag gewidmet.

1 K. Sommermeyer u. H. Magnus, Z. Naturforschg. 15 b, 770 [1960]. gleichbar, als sie nur dann vor den Folgen der direkten Bestrahlung schützen, wenn sie bereits vor der direkten Bestrahlung in die Bakterien gelangt sind. Auf der anderen Seite ist aber ihre Schutzwirkung in der Coli-Zelle, nachdem sie in die Coli-Zelle hineindiffundiert sind, nur von begrenzter Dauer, nämlich von der Größenordnung 30 bis 60 Sekunden. Im folgenden soll über diese Versuchsreihen berichtet werden. Die Züchtungsbedingungen der ColiKulturen und Strahlenquellen sind die gleichen wie in l. c. ${ }^{1}$.

\section{Versuche mit Röntgenstrahlen}

1. Eine Schutzwirkung ergibt sich nur, wenn die direkte Bestrahlung erfolgt, nachdem die aktiven Agarsubstanzen bereits in die Coli-Zelle hineindiffundiert sind. Dies zeigen die folgenden beiden Versuche (s. Abb. 1).

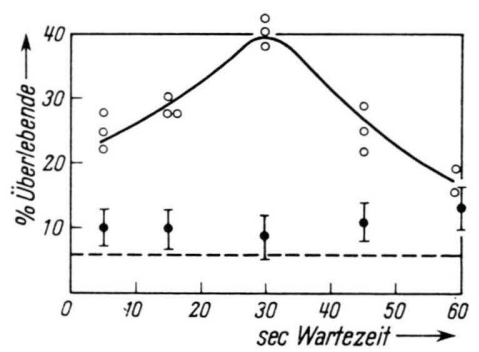

Abb. 1. Versuch Ia und Ib. Röntgenstrahlen: Agarvorbestrahlung allein $50 \%$ Überlebende, direkte Bestrahlung allein 13\% Ủberlebende, Bestrahlung: Dauer 1 Minute. O erst Agarstoffe, dann direkte Bestrahlung; ‘ erst direkte Bestrahlung, dann Agarstoffe; $\cdots$ bei Additivität, Pipettierzeit 3 Sekunden.

2 K. Sommermeyer u. H. Magnus, Z. Naturforschg. 17 b, 173 [1962]. 


\section{Versuch a}

Agar wird bestrahlt und B. coli sofort nach der Bestrahlung auf den Agar aufgebracht. Nach einer Wartezeit wird das auf dem Agar befindliche B. coli bestrahlt, die Wartezeit wird variiert. Wartezeit ist dabei die Zeitdifferenz zwischen Beendigung der Agarbestrahlung und Beginn der direkten Coli-Bestrahlung.

$$
\mathrm{Versuch} \mathrm{b}
$$

$B$. coli wird auf eine Glasunterlage aufgebracht und in diesem Zustand bestrahlt. Ganz unabhängig davon wird eine Agarschicht von etwa $1 \mathrm{~mm}$ Dicke bestrahlt und sofort nach Beendigung der Bestrahlung auf das $B$. coli aufgelegt. Die Zeitdifferenz zwischen der direkten $B$. coli-Bestrahlung auf der Glasunterlage und der Beendigung der Agarbestrahlung bzw. dem Aufbringen des Agars auf das B. coli wird variiert. Als Wartezeit bezeichnen wir die Zeitdifferenz zwischen Beendigung der direkten B. coli-Bestrahlung und der Beendigung der Agarbestrahlung bzw. dem Aufbringen des bestrahlten Agars.

Bei beiden Versuchen war die Dosisleistung der direkten Bestrahlung und der Agar-Bestrahlung $12000 \mathrm{r} /$ Minute. Bei der direkten Bestrahlung des $B$. coli war die Bestrahlungsdauer 1 min und es ergab sich bei Vornahme der Bestrahlung auf unbestrahlten Agar eine Überlebensrate von rund 13 Prozent. Die Bestrahlungsdauer bei der Agarbestrahlung betrug 5 Minuten. Bei sofortigem Aufbringen von B. coli auf den so vorbestrahlten Agar ergab sich eine Überlebensrate von etwa 50 Prozent. Bei Kombination der direkten Bestrahlung und der Agarvorbestrahlung muß sich also eine Überlebensrate von $6,5 \%$ ergeben, wenn die Wirkungen der Agar-Substanzen und der direkten Bestrahlung völlig unabhängig voneinander, also rein additiv sind.

$$
\text { Versuchsergebnisse }
$$

Versuch a. Er zeigt den Antagonismus zwischen der direkten Bestrahlung und den aktiven Agarsubstanzen in der Coli-Zelle. Dieser kommt aber erst mit steigenden Wartezeiten zwischen Agarbestrahlung und direkter Bestrahlung voll zur Entwicklung und ergibt bei $30 \mathrm{sec}$ Wartezeit ein Maximum der Überlebendenraten; dort erhält man statt der erwarteten Überlebensrate von der Größenordnung $7 \%$ eine Überlebensrate von 40 Prozent.

Versuch b. Läßt man die Agarsubstanzen erst nach der direkten Bestrahlung auf die ColiZellen einwirken, so tritt keine Schutzwirkung durch die Agarsubstanzen ein, und die Wirkungen der direkten Bestrahlung und der Agarbestrahlung sind additiv, wenn auch nicht im vollen Ausmaß. Es ergibt sich eine Überlebensrate von rund $10 \%$, und zwar fast unabhängig von der Wartezeit.
Während bei dem Versuch a B. coli auf den Agar sofort nach Beendigung der Vorbestrahlung des Agars aufgebracht wurde, wurde in den folgenden Versuchen auch noch die Zeit zwischen der Beendigung der Agarbestrahlung und dem Aufpipettieren von B. coli auf den Agar (Pipettierzeit) variiert. Um ein klareres Bild der vorliegenden Gesetzmäßigkeiten zu erhalten, wurde außerdem noch die Dosisleistung bei der direkten Bestrahlung erhöht bzw. die Bestrahlungsdauer vermindert. Die Dosisleistung bei der direkten Bestrahlung betrug $100000 \mathrm{r} / \mathrm{min}$, die Bestrahlungsdauer 6 Sekunden.

Versuch c. Die Versuchsdaten sind bis auf die kürzere direkte Bestrahlungsdauer die gleichen wie bei Versuch a. Insbesondere wurde B. coli sofort nach Beendigung der Vorbestrahlung auf den Agar aufpipettiert (Pipettierzeit ungefähr $3 \mathrm{sec}$ ).

Versuch d. Bei sonst gleichen Daten wurde B. coli nicht sofort nach Beendigung der Agarvorbestrahlung aufpipettiert, sondern erst nach $30 \mathrm{sec}$ (Pipettierzeit $30 \mathrm{sec}$ ).

Versuch e. Bei sonst gleichen Daten betrug die Pipettierzeit 60 Sekunden.

Bei den Versuchen I c, d, e, ist wie oben die Wartezeit die Zeitdifferenz zwischen Beendigung der Vorbestrahlung des Agars und Beginn der direkten Bestrahlung.

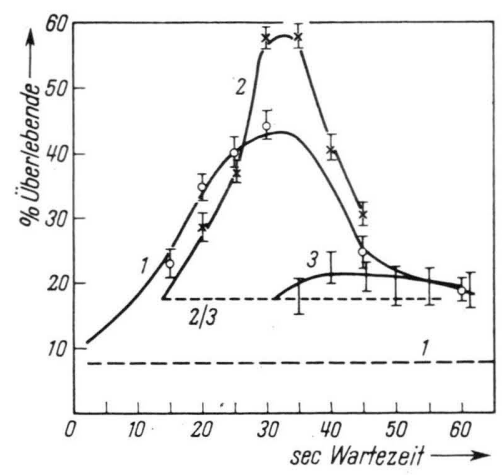

Abb. 2. Versuche I c, d, e. Röntgenstrahlen: Agarbestrahlung allein 50\% Überlebende, direkte Bestrahlung allein $18 \%$ Überlebende, direkte Bestrahlung Bestrahlungsdauer 6 Sekunden. 1 Pipettierzeit $3 \mathrm{sec}, 2$ Pipettierzeit $30 \mathrm{sec}, 3$ Pipettierzeit 60 Sekunden.

Ergebnisse: Bei den Versuchen c und d steigt die Überlebensrate mit steigender Wartezeit an und erreicht ein Maximum bei einer Wartezeit von etwa 60 Sekunden. Die zeitliche Lage des Maximums hängt also lediglich von der Zeit ab, die nach der Beendigung der Agarvorbestrahlung verflossen 
ist. Sie ist unabhängig davon, ob B.coli auf den Agar sofort nach der Vorbestrahlung aufpipettiert wird oder ob man dabei Zeit verstreichen läßt. Nach Überschreiten des Maximums fällt die Überlebensrate mit einer Halbwertszeit ab, die etwa zwischen 20 und $40 \mathrm{sec}$ liegt. Während die Lage des Maximums fast unabhängig von der Pipettierzeit ist, ist die Höhe des Maximums davon abhängig. Wird B. coli sofort auf den Agar aufpipettiert, so beträgt das Maximum der Überlebensrate etwa 40 Prozent. Bei einer Pipettierzeit von $30 \mathrm{sec}$ ist das Maximum etwas höher und liegt bei $60 \%$ Überlebensrate. Bei $60 \mathrm{sec}$ Pipettierzeit ist der Schutzeffekt geringfügig.

Deutung der Versuchsergebnisse

Zur Deutung der Versuchsergebnisse gehen wir von der Voraussetzung aus, daß bei der direkten Bestrahlung von B. coli die Schädigung der strahlenempfindlichen Strukturen durch sehr kurzlebige aktive Moleküle (vielleicht organische Peroxyd-Radikale mit einer Lebensdauer jedenfalls unter $1 \mathrm{sec}$ ) erfolgt, welche entweder in dem Plasma entstehen und $\mathrm{zu}$ den strahlenempfindlichen Strukturen hindiffundieren oder durch direkte Treffer ${ }^{1}$ unmittelbar in den strahlenempfindlichen Strukturen erzeugt werden. Die strahlenempfindlichen Strukturen können wahrscheinlich mit Chromosomen identifiziert werden. Eine Reihe von Argumenten ${ }^{2}$ sprechen dafür ${ }^{1}$, daß bei der direkten Bestrahlung der ColiZelle mit $\alpha$-Strahlen die Wirkung von im Plasma erzeugten aktiven Molekülen bzw. Radikalen überwiegt und bei der direkten Röntgenbestrahlung die Wirkung der direkten Treffer in den strahlenempfindlichen Strukturen.

Solange die Schutzsubstanzen im Agar vorhanden und noch nicht abgeklungen sind, diffundieren sie auch in die Coli-Zelle hinein. Offe... oar lagern sie sich zu einem großen Teil an die strahitnemp, findlichen Strukturen oder auch an andere Partikel im Plasma an, welche die Zellmembran nicht durchdringen können. Sie reichern sich daher in den Bakterien an, verlieren aber an den Anlagerungsorten wiederum ihre Aktivität. Nach den Versuchsergebnissen ist nach einer Wartezeit von $60 \mathrm{sec}$ die Diffusion der Schutzsubstanzen in die Coli-Zelle im wesentlichen abgeschlossen, die Halbwertszeit der Schutzsubstanzen im Agar liegt also zwischen 30 und 60 Sekunden. Das Abklingen der in der Coli.

1 oder es mögen auch aktive Wasserradikale mit extrem kleiner Diffusionslänge zur Wirkung kommen.
Zelle adsorbierten Schutzsubstanzen erfolgt, wie die Versuche zeigen, mit einer ähnlichen Halbwertszeit, sie liegt also gleichfalls zwischen 30 und 60 Sekunden. Jedenfalls trifft man bei einer Wartezeit von $60 \mathrm{sec}$ eine maximale Menge von Schutzsubstanzen in der Coli-Zelle an, und wir erhalten so bei einer Wartezeit von $60 \mathrm{sec}$ ein Maximum der Überlebenskurve.

Wie erklärt sich nun die Wirkung der Schutzsubstanzen? Die einfachste Annahme ist hierbei, daß die bei der direkten Bestrahlung erzeugten aktiven Moleküle oder Radikale, mögen sie nun im Plasma oder in den Chromosomen bzw. in ihrer unmittelbarsten Umgebung entstehen, mit den Schutzsubstanzen reagieren. Durch Kombination oder durch Disproportionierung büßen dabei beide Arten von aktiven Molekülen bzw. Radikalen ihre Aktivität bzw. ihren Radikalcharakter ein.

Es ist kein Zweifel, daß mit steigender Pipettierzeit immer weniger Schutzsubstanzen in die ColiZelle hineingelangen, man sollte daher erwarten, daß mit steigender Pipettierzeit die Höhe des Maximums der Überlebensrate fortgesetzt zurückgeht. In Wirklichkeit ist aber das Maximum bei 30 sec Pipettierzeit etwas höher als bei einer Pipettierzeit von einigen sec und nimmt dann erst bei größeren Pipettierzeiten rasch ab.

Durch diesen Befund wird die Frage aufgeworfen, wie weit die im Agar entstehenden Schutzsubstanzen identisch sind rnit den dort gebildeten inaktivierenden Substanzen. Aus dem experimentellen Befund geht zunächst hervor, daß die als Schutzsubstanzen wirkenden Substanzen im Agar eine Lebensdauer haben, die ein wenig größer ist als die Lebensdauer der inaktivierenden Substanzen. Eine Inaktivierung des $B$. coli erfolgt nicht nur durch die direkte Bestrahlung, sondern auch durch die aus dem vorbestrahlten Agar herandiffundierenden inaktivierenden Substanzen. Bei einer Pipettierzeit von $30 \mathrm{sec}$ kommt die Inaktivierung durch die inaktivierenden Substanzen in Fortfall, daher liegt das Maximum der Überlebensrate höher als bei einer Pipettierzeit von nur einigen Sekunden.

Die inaktivierenden Agar-Substanzen werden im Agar durch mindestens zwei Treffer erzeugt ${ }^{1}$. Nachdem sich ergeben hat, daß die inaktivierenden Substanzen grundsätzlich nicht mit den

\footnotetext{
2 Vor allem Inaktivierung nach Bestrahlung in der Umgebung des Gefrierpunktes.
} 
Schutzsubstanzen identisch sind, bleibt noch der Reaktionsmechanismus zu untersuchen, nach dem die Schutzsubstanzen im Agar entstehen.

Für die inaktivierenden Agar-Substanzen ist nach l. c. ${ }^{1}$ folgendes charakteristisch:

1. Ihre Konzentration im Agar strebt mit steigender Dosis einem Grenzwert zu.

2. Die Aufbauzeit dieser Grenzkonzentration ist viel größer als die Abklingzeit nach Abschalten der Bestrahlung.

3. Auch schon bei kleineren Dosen, bei denen die Grenzkonzentration noch nicht erreicht ist, haben die inaktivierenden Agar-Substanzen im Agar nach dem Abschalten der Bestrahlung dieselbe Halbwertszeit wie bei sehr hohen Dosen.

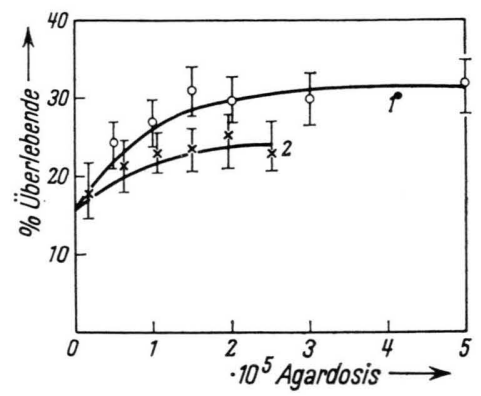

Abb. 3. Versuch If. Röntgenstrahlen: Direkte Bestrahlung allein 16\% Überlebende, Bestrahlung: Dauer 6 sec, Pipettierzeit $3 \mathrm{sec}$, Wartezeit 30 Sekunden. Agarbestrahlung: 1 Dosisleistung $100000 \mathrm{r} / \mathrm{min}$; 2 Dosisleistung $12000 \mathrm{r} /$ Minute.

Zur Aufklärung des Reaktionsmechanismus bei der Bildung der Schutzsubstanzen haben wir die entsprechenden Versuche ausgeführt:

Versuch f (Abb. 3). Abhängigkeit der Schutzwirkung von der Agardosis. Hierfür haben wir die gleichen Versuchsdaten wie bei Versuch c (s. Abb. 2) gewählt. Man entnimmt aus Abb. 2, daß nach der Agarvorbestrahlung mit $50000 \mathrm{r}$ (Dosisleistung von $100000 \mathrm{r} / \mathrm{min}$ ) bei einer Pipettierzeit von einigen sec und bei einer direkten Bestrahlung mit $10000 \mathrm{r}$ sich mit einer Wartezeit von $30 \mathrm{sec}$ eine Überlebensrate von etwa $25 \%$ ergibt, während bei Unabhängigkeit der direkten Strahlenwirkung und der Agarwirkung die Überlebensrate $8 \%$ wäre.

Bei sonst gleichen Daten wurde die Agardosis gesteigert, und zwar bis 500000 r. Abb. 3 zeigt, da $\beta$ sich genau wie bei den inaktivierenden Substanzen die Konzentration der Schutzsubstanzen im Agar einem Grenzwert entsprechend etwa 30\% Überlebenden zustrebt. Das gleiche Ergebnis findet man bei einer Dosisleistung von $12000 \mathrm{r} / \mathrm{min}$ (Grenzwert entsprechend etwa $25 \%$ Überlebenden), wenigstens bei der letzteren Dosisleistung ist die Aufbauzeit $(\approx 10 \mathrm{~min})$ viel länger als die Abklingzeit der Schutzsubstanzen im Agar $(<1$ min $)$.

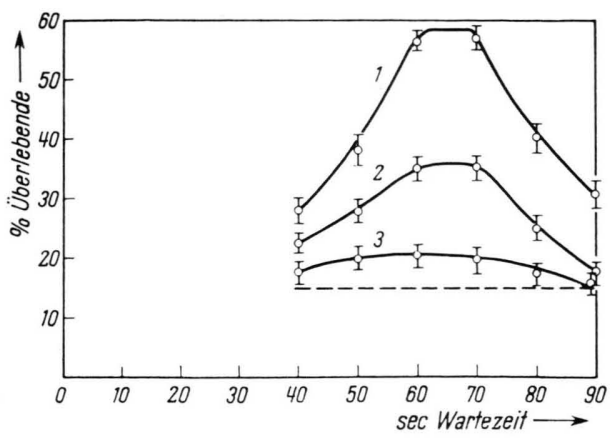

Abb. 4. Röntgenstrahlen (Versuch Ig). Direkte Bestrahlung 16\% Uberlebende, Bestrahlung: Dauer $6 \mathrm{sec}$, Pipettierzeit $30 \mathrm{sec}$, Agardosen: $150000 \mathrm{r}, 233000,315000 \mathrm{r}$, $106000 \mathrm{r} /$ Minute.

Versuch g (Abb. 4). Überlebenskurven bei kleinen Agardosen. In Abb. 2 ist eine Überlebenskurve (Überlebendenrate in Abhängigkeit von der Wartezeit) wiedergegeben, die mit einer Pipettierzeit von $30 \mathrm{sec}$, einer Agardosis von $50000 \mathrm{r}$ und einer direkten Dosis von $10000 \mathrm{r}$ gewonnen wurde (Versuch I d). Bei genau den gleichen Daten, jedoch geringeren Agardosen, wurden weitere Überlebenskurven aufgenommen. Bei den kleinen Agardosen (nämlich $33000 \mathrm{r}$ ) geht zwar die Höhe des Maximums der Überlebensrate zurück, die Lage des Maximums und die Form der Überlebenskurve bleibt jedoch genau die gleiche.

Aus den beiden Versuchsreihen $\mathrm{f}$ und $\mathrm{g}$ ist $\mathrm{zu}$ schließen, daß die Schutzsubstanzen grundsätzlich nach dem gleichen Mechanismus wie die inaktivierenden Substanzen entstehen. Also auch die Schutzsubstanzen benötigen zu ihrer Entstehung im Agar mindestens zwei Treffer. Offenbar besitzen die inaktivierenden Moleküle und die Schutzmoleküle eine sehr ähnliche chemische Struktur. Da die Lebensdauer der Schutzsubstanzen im Agar etwas länger ist als die Lebensdauer der inaktivierenden Substanzen, kann man jedoch nicht annehmen, daß die Schutzwirkung der aktiven Agarmoleküle proportional ihrer inaktivierenden Wirkung ist. Man muß vielmehr zwischen aktiven Agarmolekülen mit ihrer relativ hohen Schutzwirkung und aktiven Agarmolekülen mit einer relativ hohen Inaktivierungs-Wahrscheinlichkeit unterscheiden. 


\section{Versuche mit $\alpha$-Strahlen}

Bei Anwendung von $a$-Strahlen werden im Agar grundsätzlich mit dem gleichen Mechanismus Schutzsubstanzen mit grundsätzlich den gleichen Eigenschaften gebildet wie bei Anwendung von Röntgenstrahlen. Insbesondere vergewisserten wir uns auch, daß die Schutzwirkung nur auftritt, wenn die Schutzsubstanzen vor Anwendung der direkten Bestrahlung in den Agar gelangen.

Ein bemerkenswerter qualitativer Unterschied besteht jedoch zu den Versuchen mit Röntgenstrahlen. Bei der Anwendung von Röntgenstrahlen -und sofortigem Aufpipettieren liegen bei der meist angewandten Agardosis die Überlebensraten bei allen Versuchen immer unter $50 \%$, d. h. unter der Überlebensrate bei alleiniger Anwendung der Agarvorbestrahlung. Offenbar bleibt die Inaktivierung durch die inaktivierenden Substanzen quantitativ die gleiche, auch wenn zusätzlich eine direkte Bestrahlung angewandt wird; durch die direkte Bestrahlung wird also die inaktivierende Wirkung der Agarmoleküle, d. h. auch die Konzentration der inaktivierenden Agarmoleküle in der Coli-Zelle praktisch nicht vermindert.

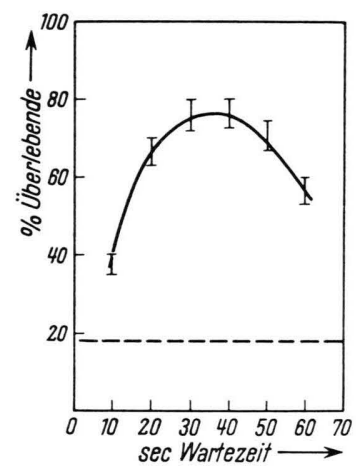

Abb. 5. Versuch II. a-Strahlen: Pipettierzeit $3 \mathrm{sec,} \mathrm{Agar-}$ bestrahlung allein $50 \%$ Überlebende, direkte Bestrahlung allein 38\% Überlebende, Bestrahlung: Dauer 40 Sekunden.

Anders sind in dieser Hinsicht die Verhältnisse bei den $\alpha$-Strahlen. Der Agar bzw. seine Oberflächenschicht von $30 \mu$ Dicke erhielt eine Dosis von $60000 \mathrm{rad}$ in 5 Minuten. Bei sofortigem Aufpipettieren von B. coli ist die Überlebensrate 50 Prozent. Eine direkte Bestrahlung von $B$. coli auf unbestrahltem Agar von $40 \mathrm{sec}$ Dauer mit dem gleichen Polonium-Präparat ergibt eine Überlebensrate von 38 Prozent. Die Abbildung zeigt die Überlebenskurve bei direkter Bestrahlung auf vorbestrahltem Agar bei der Pipettierzeit von etwa 3 Sekunden. Man stellt fest, daß die Überlebendenrate mit steigender Wartezeit bis zu 80\% ansteigt, obwohl sofort nach Beendigung der Agar-Vorbestrahlung mit $B$. coli aufpipettiert wird.

Wie schon oben erwähnt, sprechen nach l. c. ${ }^{1}$ einige Argumente dafür, daß die direkten $\alpha$-Durchgänge durch $B$. coli im Plasma diffusible aktive Substanzen erzeugen, welche dann zu den strahlenempfindlichen Strukturen diffundieren und diese schädigen. Aus dem Ver- suchsergebnis muß man nun schließen, daß die inaktivierenden Agarsubstanzen mit den bei den direkten Durchgängen durch das Coli-Plasma erzeugten Substanzen reagieren und sie sich gegenseitig zerstören. Im Falle der $\alpha$-Strahlen ist offenbar die Konzentration der in die Coli-Zelle hineindiffundierten inaktivierenden Agarsubstanzen von der gleichen Größenordnung wie die Konzentration der direkt erzeugten Radikale oder sie kann nur noch kleiner sein. Nur so kann sich die hohe Überlebendenrate von $80 \%$ ergeben. Auf der anderen Seite muß dann den durch $a$-Strahlen erzeugten aktiven Agarmolekülen eine viel höhere Inaktivierungs-Wahrscheinlichkeit pro aktives Agarmolekül zugeschrieben werden als den durch Röntgenstrahlen erzeugten. Dieser Schluß ist in Übereinstimmung mit Ergebnissen von (2).

\section{Kombination von Röntgenstrahlen und $\alpha$-Strahlen}

Bei diesen Versuchen wurde wiederum die Dosis sowohl bei Röntgenstrahlen als auch $\alpha$-Strahlen bei der Agarvorbestrahlung so gewählt, daß die Überlebendenrate bei sofortiger Pipettierzeit $50 \%$ betrug; die Dosen bei der direkten Bestrahlung von B. coli auf unbestrahlten Agar wurden so gewählt, $\mathrm{da}$ sich ungefähr $20 \%$ Überlebensrate ergaben. Jedoch waren die Dosisleistungen geringer als bei den Versuchen I a, d, e, die Bestrahlungsdauer der direkten Bestrahlung betrug bei den $\alpha$-Strahlen 2 min und bei den Röntgenstrahlen 1 Minute. Bei den Versuchen wurde immer sofort nach der Vorbestrahlung des Agars B. coli aufpipettiert. Wenn man bei den angegebenen Daten die Vorbestrahlung und die direkte Bestrahlung mit Röntgenstrahlen ausführt, steigt die Überlebensrate bei etwa $30 \mathrm{sec}$ Wartezeit auf etwa 45 Prozent. Wenn man mit diesen Daten Vorbestrahlung und direkte Bestrahlung mit $\alpha$-Strahlen ausführt, so ergibt sich eine maximale Überlebensrate von $70 \%$, und zwar wiederum bei etwa $30 \mathrm{sec}$ Wartezeit.

a) Vorbestrahlung des Agars mit Röntgenstrahlen, direkte Bestrah lung mit $\alpha-\mathrm{Strahlen.} \mathrm{Bei} \mathrm{diesem} \mathrm{Versuch}$ ergeben sich mit steigender Wartezeit Überlebendenraten, die zwar bei einer Wartezeit von $30 \mathrm{sec}$ nahezu $50 \%$ erreichen, diese jedoch nicht übersteigen.

b) Vorbestrahlung des Agars mit $\alpha$-Strahlen, direkte Bestrahlung mit Röntgenstrahlen. Hierbei treten nur ganz geringfügige Schutzwirkungen auf und die Überlebendenrate bleibt bei Steigerung der Wartezeit immer unter 20\% (zwischen 10 und 20 Prozent). 
Deutung der Versuche

\section{Versuch a}

In II waren wir in Übereinstimmung mit l. c. ${ }^{2} \mathrm{zu}$ dem Schluß gelangt, daß nach der Vorbestrahlung des Agars mit Röntgenstrahlen viel mehr inaktivierende Agarmoleküle zu der Coli-Zelle gelangen als nach äquivalenter Vorbestrahlung mit $\alpha$-Strahlen (äquivalente Vorbestrahlung heißt bei beiden Strahlenarten und sofortigem Aufpipettieren des B. coli gleiche Überlebensrate). Die Anzahl der nach der Röntgenvorbestrahlung in die Coli-Zelle hineindiffundierten inaktivierenden Moleküle wird daher durch Reaktionen mit den beim direkten $\alpha$-Durchgang entstandenen aktiven Molekülen praktisch nicht vermindert und die maximale Überlebendenrate bleibt knapp unter 50 Prozent.

\section{Versuch $b$}

Hierbei kann man von der schon oben erwähnten speziellen Annahme l. c. ${ }^{1}$ ausgehen, daß bei der direkten Bestrahlung von B. coli mit Röntgenstrahlen die Wirkung der direkten Treffer durch die strahlenempfindlichen Strukturen überwiegt. Wenn eine merkliche Schutzwirkung zustande kommen soll, müssen daher die strahlenempfindlichen Strukturen eine dichte Besetzung mit Schutzmolekülen aufweisen. Diese dichte Besetzung ergibt sich zwar bei einer Vorbestrahlung des Agars mit Röntgenstrahlen, aber nicht bei einer Vorbestrahlung mit $\alpha$-Strahlen, weil bei der Vorbestrahlung mit $\alpha$-Strahlen nicht nur viel weniger inaktivierende Agar-Moleküle, sondern auch viel weniger Schutzmoleküle in die Coli-Zelle als nach der Vorbestrahlung mit Röntgenstrahlen gelangen.

\section{Die Diffusionslängen der inaktivierenden Substanzen im Agar bei Anwendung von $\alpha$-Strahlen}

In den vorangegangenen Ausführungen konnten wir den schon in l. c. ${ }^{2}$ gemachten Schluß bestätigen, daß unter äquivalenten Bedingungen (Agarvorbestrahlungen die bei sofortigem Aufpipettieren eine gleiche Überlebensrate erzeugen) aus dem mit Rönt. genstrahlen vorbestrahlten Agar sehr viel mehr inaktivierende Moleküle in die Coli-Zelle hineindiffundieren wie aus dem mit $\alpha$-Strahlen vorbestrahlten Agar, bzw. daß im ersten Fall die aktiven Agarmoleküle eine geringere Inaktivierungs-Wahrschein- lichkeit pro aktives Agarmolekül besitzen als im letzteren Fall.

Außer von der Ausbeute ${ }^{3}$ für die Entstehung der inaktivierenden Substanzen im Agar ist die Zahl der zu der Coli-Zelle diffundierenden aktiven Moleküle vor allem von ihrer Diffusionslänge abhängig (vgl. l.c. ${ }^{1}$ ). Diese Diffusionslänge hatte sich bei den Röntgenstrahlen zu etwa $120 \mu$ ergeben.

Wir haben inzwischen auch Versuche angestellt, um die Diffusionslänge im Falle der Anwendung von $\alpha$-Strahlen zu ermitteln. Zu diesem Zwecke wurden zunächst, ebenso wie bei den Röntgenstrahlen, die Agar-Schichtdicken bis auf $40 \mu$ vermindert und nach der Vorbestrahlung B. coli auf der Agar-Seite, auf der die Bestrahlung erfolgte, aufpipettiert. Der Versuch ergab nicht das geringste Anzeichen einer Abnahme der Schädigungsrate, die bei dem benutzten Polonium-Präparat $50 \%$ betrugen, mit abnehmender Schichtdicke.

Bei einem weiteren Versuch wurde das B. coli auf einer Glasunterlage aufgebracht und auf das $B$. coli eine $80 \mu$ dicke Agarschicht aufgelegt und von oben mit den $\alpha$-Strahlen bestrahlt. Bei der Anordnung sind die Bakterien vor der direkten Bestrahlung vollkommen geschützt. Wir hatten erwartet, daß die inaktivierenden Substanzen in großen Mengen durch die $80 \mu$ dicke Schicht zu den Bakterien hindiffundieren und daß sich so beträchtliche Inaktivierungen ergeben würden. Trotz der großen Präparatstärke ergab sich auch bei Bestrahlungsdauern bis $8 \mathrm{Stdn}$. nicht die geringste Andeutung einer Inaktivierung der Bakterien.

Aus beiden Versuchen geht hervor, daß offenbar die Diffusionslängen bei der Anwendung von $\alpha$-Strahlen viel kleiner sind (sicher $<40 \mu$ ) als bei der Anwendung von Röntgenstrahlen. Es ist also auch durch diese Versuche bestätigt worden, daß zu der Coli-Zelle nach der $\alpha$-Bestrahlung des Agars viel weniger inaktivierende Moleküle gelangen als nach der Röntgenbestrahlung, und die durch die $\alpha$-Bestrahlung entstandenen inaktivierenden Agar-Moleküle eine viel größere Inaktivierungs-Wahrscheinlichkeit besitzen als die durch Röntgenstrahlen erzeugten.

Die größere Aktivität der inaktivierenden AgarMoleküle nach Anwendung der $\alpha$-Strahlen ist sehr wahrscheinlich auch die Ursache dafür, daß sie im

${ }^{3}$ d. h. Anzahl an im Agar pro $100 \mathrm{eV}$ absorbierter Energie entstehenden Molekülen. 
Agar eine viel kleinere Diffusionslänge besitzen. Die Vermutung liegt nahe, daß ihre Bewegung durch das feste Agargerüst behindert wird. Wir nehmen an, daß sie vorübergehend durch den Agar festgehalten werden, „g-Wert" bei kleinen Dosen.

Unter der Annahme, daß die Ausbeute bei der Erzeugung der inaktivierenden Agarmoleküle durch Röntgenstrahlen die gleiche ist wie bei der Erzeugung durch $\alpha$-Strahlen, folgt nach l.c. ${ }^{1}$ aus allen Daten, daß bei äquivalenten Agarbestrahlungen rund 10-mal mehr inaktivierende Moleküle nach Röntgenbestrahlung des Agars zu den Coli-Zellen diffundie- ren als nach $\alpha$-Bestrahlung. Dabei wurden bei beiden Strahlenarten gleiche Diffusionslängen angenommen. Nachdem nun festgestellt ist, daß die Diffusionslänge bei Anwendung der $\alpha$-Strahlen höchstens $30 \%$ der Diffusionslänge bei Anwendung der Röntgenstrahlen beträgt, können wir schließen, daß im ersteren Fall mindestens 30-mal mehr inaktivierende Agar-Moleküle zur Coli-Zelle diffundieren als im letzteren Fall.

Der Deutschen Forschungsgemeinschaft danken wir für Ünterstützung der Arbeit.

\title{
Uber den Einfluß der Kulturbedingungen auf die Strahlenempfindlichkeit der Glucoseoxydation in Bacterium cadaveris*
}

\author{
Von H. PaUly
}

Aus dem Max-Planck-Institut für Biophysik, Frankfurt am Main

(Direktor: Prof. Dr. Dr. h. c. Dr. h. c. B. Rajewsky)

(Z. Naturforschg. 18 b, 23-25 [1963] ; eingegangen am 6. Juni 1962)

\begin{abstract}
Bei B. cadaveris, die in einem an organischen Substanzen reichen Medium kultiviert wurden, nimmt der $\mathrm{O}_{2}$-Verbrauch pro Zeiteinheit bei Glucoseveratmung mit der Röntgenstrahlendosis ab, während bei Bakterien, die in einem Salzmedium gewachsen sind, die Atmung bis zu einer Dosis von 2-3 Mr erst ansteigt, um erst bei höheren Dosen abzufallen. Die Atmung wird erst bei Dosen in der Größenordnung von 1 Million $\mathrm{r}$ merklich beeinflußt.

Die Atmung der Bakterien ist damit unter den hier untersuchten Bedingungen noch strahlenresistenter als die Gewebeatmung von Säugetierzellen ${ }^{4-12}$.
\end{abstract}

In einer früheren Mitteilung ${ }^{1}$ wurde gezeigt, daß

1. die Glucoseveratmung von E. coli sehr röntgenstrahlenresistent ist und erst durch Dosen in der Größenordnung von 1 Million $\mathrm{r}$ gehemmt wird, und daß

2. die Dosiseffektkurven von den Kulturbedingungen abhingen. Die Dosisabhängigkeit konnte interpretiert werden auf Grund der Annahme, daß die Röntgenstrahlen einige der bei der Glucoseoxydation beteiligten Enzyme inaktivieren.

In einer weiteren Mitteilung ${ }^{2,3}$ mußte jedoch auf

* Gewidmet Herrn Prof. Dr. Dr. h. c. Dr. h. c. B. Rajewsky zum 25-jährigen Bestehen des „Max-Planck-Instituts für Biophysik".

1 B. Rajewsky, G. Gerber u. H. Pauly, Naturwissenschaften 43, 228 [1956].

2 H. Pauly, Habilitationsschrift, Frankfurt/M. 1959.

3 B. Rajewsky u. H. Pauly, im Druck.

4 D. Billen, G. E. Stapleton u. A. Hollaender, J. Bacteriol. 65, 131 [1953].

5 K. Aurand u. H. Pauly, Z. Naturforschg. 9 b, 506 [1954].

6 M. L. Mendelsohn, J. Physiol. 180, 599 [1955].
Grund einer Erhöhung der Atmung geschlossen werden, daß Röntgenstrahlen den Stoffumsatz sowohl durch die Inaktivierung der Enzymmoleküle selbst als auch durch Änderung des intrazellulären Milieus, d. h. der Geschwindigkeitskonstanten der beteiligten katalytischen Prozesse zu beeinflussen vermögen.

In dieser Arbeit wird gezeigt, daß man je nach Kulturbedingungen entweder eine Erhöhung oder eine Hemmung der Glucoseveratmung in Bacterium cadaveris nach Röntgenbestrahlung messen kann.

7 H. Maass, G. Höhne u. H. A. Künkel, Z. Naturforschg. 11 b, 593 [1956].

${ }^{8}$ H. Pauly u. B. Rajewsky, Strahlentherapie 99, 383 [1956].

9 H. Pauly u. B. Rajewsky, Progress in Radiobiology, Oliver and Boyd, Edinburgh - London 1956, 32-41.

10 B. Rajewsky, G. Gerber u. H. Pauly, Advances in Radiobiology, Oliver and Boyd, Edinburgh-London 1957, $25-32$.

11 K. Dose, F. Bresciani u. B. Rajewskx, Strahlentherapie Sonderband 43, 353 [1959].

12 H. Langendorff u. U. Hagen, Experientia [Basel] 11, I [1955]. 